\title{
Split-Bolus Single-Phase Cardiac Multidetector Computed Tomography for Reliable Detection of Left Atrial Thrombus: Comparison to Transesophageal Echocardiography
}

\section{Monophasische Doppel-Bolus-Kardio-Multidetektor- Computer- tomografie zur validen Detektion von Thromben im linken Vorhof und Vorhofohr: ein Vergleich zur transösophagealen Echokardiografie}

\author{
Authors \\ W. Staab ${ }^{1}$, C. Sohns ${ }^{2}$, P. A. Zwaka', J. M. Sohns ${ }^{1}$, A. Schwarz ${ }^{1}$, S. Schneider ${ }^{3}$, D. Vollmann ${ }^{2}$, M. Zabel ${ }^{2}$, \\ G. Hasenfuß2 ${ }^{2}$, J. Lotz ${ }^{1}$ \\ Affiliations \\ Institute for Diagnostic and Interventional Radiology, University Medical Center of Georg-August-University, Goettingen \\ Dept. of Cardiology and Pneumology, Georg-August-University Goettingen, Germany, Goettingen \\ Dept. of Medical Statistics, Georg-August-University Goettingen
}

\author{
Key words \\ - cardiac \\ - CT \\ - ultrasound
}

received $\quad 31.10 .2013$

14.2.2014

\section{Bibliography}

Dol http://dx.doi.org/

10.1055/s-0034-1366247

Published online: 11.4.2014

Fortschr Röntgenstr 2014; 186 :

1009-1015 @ Georg Thieme

Verlag KG Stuttgart · New York

ISSN 1438-9029

\section{Correspondence}

\section{Dr. Wieland Staab}

Institute for Diagnostic and

Interventional Radiology, University Medical Center of

Georg-August-University

Robert-Koch-Str. 4037075

Goettingen Germany

37075 Goettingen

Germany

Tel.: ++49/551/398965

Fax: ++49/5 51/36 9606

wstaab@gmx.de

\section{Zusammenfassung \\ $\nabla$}

Ziel: Evaluierung eines neuen Kardio-MDCT-Protokoll mit Doppel-Bolus-Injektion zur Verbesserung der Detektion von LA- oder LAA-Thromben und Reduzierung falsch positiver Befunde im Vergleich zu den Ergebnissen der transösophagealen Echokardiografie (TEE).

Material und Methoden: Insgesamt wurden 182 konsekutive Patienten mit therapierefraktärem Vorhofflimmern (VHF) vor Pulmonalvenenisolation (PVI) eingeschlossen (62,6\% männlich, Alter 64,1 $\pm 10,2$ Jahre). Zwischen November 2010 und März 2012 wurden Patienten mittels KardioMDCT und TEE vor PVI zur Evaluation der LA/LAA Anatomie und zum Thrombenausschluss untersucht. Es wurde ein Präbolus von $30 \mathrm{ml}$ und ein Hauptbolus von $70 \mathrm{ml}$ jodhaltigem Kontrastmittel appliziert, getrennt durch eine Pause von $20 \mathrm{Se}$ kunden und abschließendem NaCl-Bolus von $40 \mathrm{ml}$. Die generierten CT-Datensätze wurden im $75 \%$ RR-Intervall ausgewertet. Hier wurden Füllungsdefekte im LAA und LA analysiert. Die Ergebnisse wurden verglichen mit vorhandenem Spontankontrast (SEC) oder Thromben in der TEE. Klinische Risikostratifizierung für Thrombusbildung wurde für beide Verfahren mit dem CHADS2-Score durchgeführt. TEE und KardioMDCT wurden getrennt von den Ergebnissen der jeweils anderen Modalität ausgewertet.

Ergebnisse: Doppel-Bolus-Kardio-MDCT identifizierte 14 von 186 Patienten (7,7\%) mit Füllungsdefekten der LA-/LAA-Region. Bei diesen Patienten wurden ebenfalls Auffälligkeiten im TEE gefunden. Kardio-MDCT zeigte 2 falsch negative Befunde im Vergleich zur TEE, jedoch keine falsch positiven. Alle 5 der 14 Patienten (31,3\%) mit Thrombusnachweis im Kardio-MDCT wurden vom TEE bestätigt. Insgesamt betrug die Spezifität und Sensitivität der Kardio-MDCT 100\%, 88\%, 100\% PPW; NPW $99 \%$. Die multivariate Analyse identifizierte Bluthochdruck, Diabetes mellitus und ein CHADS2 $\geq 2$

\section{Abstract \\ $\nabla$}

Purpose: Evaluation of a new cardiac MDCT protocol using a split-bolus contrast injection protocol and single MDCT scan for reliable diagnosis of LA/LAA thrombi in comparison to TEE, optimizing radiation exposure and use of contrast agent.

Materials and Methods: A total of 182 consecutive patients with drug refractory AF scheduled for PVI (62.6\% male, mean age: $64.1 \pm 10.2$ years) underwent routine diagnostic work including TEE and cardiac MDCT for the evaluation of LA/LAA anatomy and thrombus formation between November 2010 and March 2012. Contrast media injection was split into a pre-bolus of $30 \mathrm{ml}$ and main bolus of $70 \mathrm{ml}$ iodinated contrast agent separated by a short time delay. Results: In this study, split-bolus cardiac MDCT identified 14 of 182 patients with filling defects of the LA/LAA. In all of these 14 patients, abnormalities were found in TEE. All 5 of the 14 patients with thrombus formation in cardiac MDCT were confirmed by TEE.

Conclusion: MDCT was $100 \%$ accurate for thrombus, with strong but not perfect overall results for SEC equivalent on MDCT.

Key Points:

- Patients with no filling defect or thrombus in MDCT in the LA/LAA region are unlikely to have thrombus and may undergo PVI without TEE.

- Here, the role of an additional TEE in pre-procedural management prior to PVI in patients with $\mathrm{AF}$ has to be redefined.

- Using a split-bolus injection protocol increases the diagnostic accuracy of thrombus in the LA/ LAA region.

Citation Format:

- Staab W, Sohns C, Zwaka PA et al. Split-Bolus Single-Phase Cardiac Multidetector Computed Tomography for Reliable Detection of Left 
als unabhängige prognostische Faktoren für LA-/LAA-Thrombusbildung. Es wurde kein Thrombus bei Patienten mit VHF, Alter von $\leq 50$ Jahren und einem CHADS2-Score von $\leq 1$ nachgewiesen. Schlussfolgerung: Mit dem Doppel-Bolus-Kardio-MDCT wird die Zuverlässigkeit für die Beurteilung von Thromben oder Füllungsdefekten (SEC- Äquivalent) der LA-/LAA-Region erhöht.

Kernaussagen:

- Bei Patienten ohne Füllungsdefekt oder Thrombus im MDCT, sollte diskutiert werden ob die PVI ohne vorheriges TEE durchgeführt werden kann.

- Im präprozeduralen Management vor PVI bei Patienten mit Vorhofflimmern sollte die Rolle des TEE neu definiert werden.

- Unter Verwendung des Doppel-Bolus-Injektionsprotokolls wird die diagnostische Genauigkeit zur Erfassung von Thromben in der LA-/LAA-Region erhöht.

\section{Introduction}

Atrial fibrillation (AF) is the most common sustained cardiac arrhythmia with an associated risk of thromboembolism and significant increase of morbidity and mortality. Pulmonary vein isolation (PVI) by percutaneous radiofrequency ablation has evolved as an effective therapeutic option for this entity. It is currently recommended for drug refractory and symptomatic patients [1]. Prior to PVI it is mandatory to exclude left atrial (LA) and LA appendage (LAA) thrombus in order to prevent thromboembolic events during and after PVI [2-4]. In this context, there is no available biomarker to detect the presence of atrial thrombi and imaging is considered as the standard modality to obtain this information. Multidetector computed tomography (MDCT) and transesophageal echocardiography (TEE) are used prior to catheter ablation to exclude LA/LAA thrombus and provide exact anatomical details of the LA dimensions, as well as the number and anatomy of the pulmonary veins [5-8]. TEE is considered to be the standard of reference in the assessment of LA/LAA thrombus with a reported sensitivity of $100 \%$ and specificity of $99 \%$ [4]. In addition, TEE is able to identify spontaneous echo contrast (SEC) which is thought to represent a transitional state of slow flow prior to thrombus formation [6]. Recent studies have investigated the role of MDCT in the detection of LA/LAA thrombus with conflicting results and a wide range of diagnostic accuracy [7-12]. The main problem with most of the published scan protocols is the incomplete contrast enhancement of the LAA. To assess the risk of systemic thromboembolism, a number of clinical scoring systems have been defined. The CHADS2 score has been introduced as an effective clinical tool for the stratification of patients at risk for central or peripheral thromboembolic events. CHADS2 is an acronym for heart failure, hypertension, age $>75$ years, diabetes mellitus and stroke. A negative predictive capability for thromboembolic risk is reported for low CHADS2 scores [5]. We used this novel MDCT technique with a dual-bolus contrast injection protocol in order to increase the diagnostic accuracy of cardiac MDCT in the diagnosis of LA/LAA thrombi and to compare it to the results from TEE. TEE as well as this cardiac MDCT protocol were correlated to the CHADS2 score. This study aimed to introduce an alternative noninvasive method to rule out LA/LAA thrombi with high diagnostic accuracy.
Atrial Thrombus: Comparison to Transesophageal Echocardiography. Fortschr Röntgenstr 2014; 186: 1009-1015

\section{Materials and Methods:} $\nabla$

\section{Patient population}

A total of 182 consecutive patients with drug refractory AF scheduled for PVI (62.6\% male, mean age: $64.1 \pm 10.2$ years) underwent routine diagnostic workup prior to PVI including MDCT and TEE for the evaluation of LA/LAA anatomy and to rule out thrombus formation. All diagnostic and therapeutic procedures were performed at University Hospital Goettingen between November 2010 and March 2012. In all cases MDCT and TEE were performed within 1 - 3 days prior to PVI. The analysis was approved by the local ethics committee.

\section{Multidetector computed tomography}

Contrast-enhanced cardiac MDCT was performed using a 64-slice MDCT scanner (VCT LightSpeed, GE Healthcare, Milwaukee, WI, USA), slice collimation $64 \times 0.625 \mathrm{~mm}$; rotation time $600 \mathrm{msec}$; tube voltage $100-120 \mathrm{kV}$; adaptive dose regime (auto mAs, $280-380$ ). Depending on the scan range and the patient's body weight, the calculated mean radiation dose was $8.15 \mathrm{mSv}$ (doselength product range, 137 to $537 \mathrm{mGy}$ * $\mathrm{cm}$ ). Agreement between the detection of SEC and thrombi with CT and TEE was assessed with $\mathrm{k}$ statistics. A single spiral scan was done within a single breath-hold covering an area from the aortic arch to below the diaphragm. A retrospective ECG-gated half scan algorithm was used to reconstruct the data into contiguous axial images with a slice thickness of $0.625 \mathrm{~mm}$. For this study a single phase reconstructed at $75 \%$ of the RR-interval was used for analysis. The scanner was not equipped with a prospective scan technique. Beta adrenergic blocking agents were administered before the scan procedure if the heart rate was $>70 \mathrm{bpm}$ ( $79 \%$ of the investigated patients). Sublingual nitroglycerine was not administered due to the focus of the scan on atrial and peri-atrial anatomy. A split-bolus contrast media injection protocol was used: injection of $30 \mathrm{ml}$ at $2 \mathrm{ml} / \mathrm{s}$ of iodinated intravenous contrast agent (Imeron 350, Bracco, Constance, Germany); a 20 s break followed by $70 \mathrm{ml}$ at $4 \mathrm{ml} / \mathrm{s}$ of the same contrast and a $40 \mathrm{ml}$ saline chaser at $4 \mathrm{ml} / \mathrm{s}$. Semi-automatic bolus chasing was used to detect the second contrast bolus in the ascending aorta with a threshold of 100 Hounsfield units and a delay after triggering of 6 seconds. MDCT images were analyzed by two experienced independent readers blinded to the TEE results (P.Z., W.S.) on a separate workstation (VolumeShare2 on AW 4.2, GE Healthcare, Milwaukee, WI, USA). Atrial anatomy including pulmonary veins was identified for each patient. Qualitative, visual assessment of thrombus 


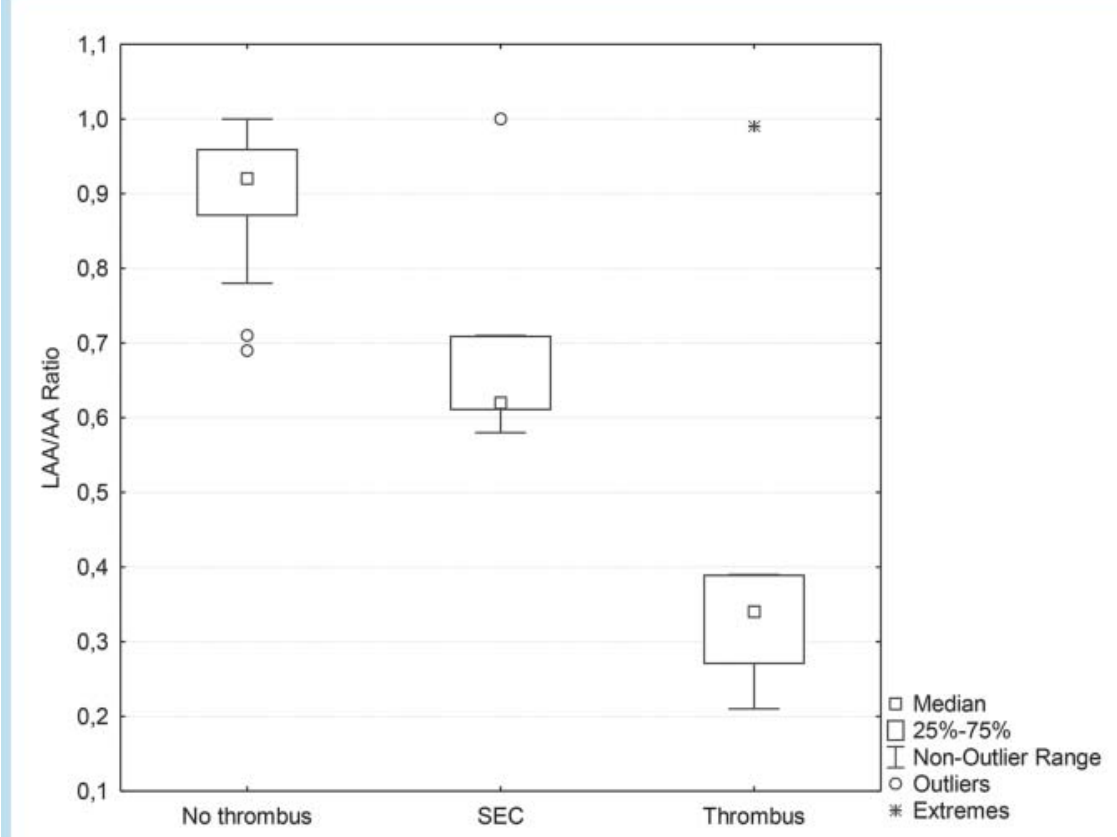

Fig. 1 Box-whisker graph shows CT attenuation values in Hounsfield units ( $y$-axis: LAA/AA ratio, indicates left atrial appendage/ascending aorta) of normal groups, spontaneous echo contrast and thrombus. Each box represents the distribution of attenuation values in the 25 th and 75 th percentiles.

Abb. 1 Box-Whisker-Diagramm zeigt CT-Dichtewerte gemessen in Hounsfield-Einheiten ( $y$-Achse: LAA-/AA-Quotient) ohne Thrombus, mit Spontankontrast und Thrombus. Jedes Feld repräsentiert die Verteilung der Dichtewerte in der 25. und 75. Perzentile.

formation in the LA or LAA was done using one of three categories: no thrombus, contrast filling defect or definite thrombus formation. A filling defect was defined as an intracavitary low attenuating oval or round lesion that represented incomplete mixing of contrast agent and blood [9]. Quantitative measurement of relative contrast enhancement of the LA and LAA to the ascending aorta was done in all patients. A $1 \mathrm{~cm}^{2}$ region of interest was placed in the LAA or LA and the lumen of the ascending aorta (AAo) on the same axial plane. Relative contrast enhancement was calculated as the ratio of LA/LAA attenuation to AAo attenuation values of $\leq 0.5$ according to previous studies $[8,17,27]$ (o Fig. 1).

\section{Echocardiography}

Transthoracic echocardiography (TTE) as well as transesophageal echocardiography (TEE) were performed in all patients. TEE was performed with a GE Vivid E9 ultrasound system (General Electric Ultrasound, Horten, Norway) using a $5.0 \mathrm{MHz}$ multiplane probe acquiring continuous cine loops of LA/LAA in $0^{\circ}-180^{\circ}$. TTE was used to determine LA size and left ventricular ejection fraction. Images were obtained according to methods described by the American Society of Echocardiography from the long axis, parasternal long and short axis, apical four-chamber and two-chamber views [13]. Highly experienced cardiologists performed and interpreted all TEEs. They were blinded to the patient's history and results from other procedures such as MDCT. LA/LAA thrombus was defined as an intracavitary echogenic mass that could be differentiated from the surrounding tissue in at least two imaging planes. Thrombus was defined as a distinct intracavitary echodense or echolucent mass in comparison to dense non-clearing SEC, defined as a slow swirling smoke-like echodensity $[8,14,15]$. The teams of TEE/TTE and cardiac MDCT were blinded to the results of the other modality during the assessment of LA/LAA thrombus formation.

\section{Clinical risk factors and anticoagulation}

The CHADS2 scoring system [16-18] was used for the stratification of patients at risk for thromboembolic events. The scoring sys- tem assigns one point for the presence of heart failure, age $>75$, diabetes mellitus and hypertension and two points for prior stroke or transitory ischemic attack (TIA). The CHADS2 score was calculated at the time of TEE. Further risk factors of LA/LAA thrombus like chronic kidney disease, valvular disease, cardiomyopathy and LA size were evaluated and documented but not included in the CHADS2 score [14]. The pre-procedural anticoagulation regime was adapted to the CHADS2 score. Phenprocoumon was used in the high-risk group (CHADS2 score $>1$ ) with a target INR of 2.0 3.0. In the intermediate group (CHADS2 score $=1$ ), anticoagulation therapy was based on the decision of the referring cardiologist. Patients in the low-risk group (CHADS2 score $=0$ ) received aspirin or no anticoagulation therapy. Prior to catheter ablation, patients at high and intermediate risk were treated with phenprocumon for at least four weeks. Five days before catheter ablation, the patients were instructed to stop phenprocumon therapy. Bridging therapy with heparin derivatives (enoxaparin) was used in the high-risk group (100 IU/kg, s. c. twice a day).

\section{Statistical analysis}

Biostatistics were planned and performed by the local Department of Medical Statistics, University Hospital Goettingen. Student's ttests and Fisher's exact tests were used to compare population averages and the statistical significance of categorical population differences or Chi-square test for categorical variables for independence between groups. Sensitivity, specificity, negative (NPV) and positive predictive values (PPV) were assessed assuming TEE as the reference standard for thrombus detection. Correlation analysis was performed using the Pearson coefficient ( $r$ ).

\section{Results}

The demographic characteristics of all 182 consecutive patients are summarized in $\bullet$ Table 1 . The image quality of all 182 consecutive MDCT examinations was considered to be diagnostic for the evaluation of intracardiac findings. In all patients an LAA 
Table 1 Patient demographic characteristics.

Tab. 1 Basisdaten der Studienpopulation.

\begin{tabular}{|lc|}
\hline male & $114(62.6 \%)$ \\
\hline female & $68(37.4 \%)$ \\
\hline age, mean & $64.1 \pm 10.2$ \\
\hline age $\geq 75$ years & $15(8.2 \%)$ \\
\hline mean ejection fraction & $54.15 \pm 6.08$ \\
\hline paroxysmal atrial fibrillation & $119(65.4 \%)$ \\
\hline persistent atrial fibrillation & $63(34.6 \%)$ \\
\hline LA size, mm & $45.40 \pm 6.92$ \\
\hline cardiomyopathy & $9(4.9 \%)$ \\
\hline mitral/aortic valve disease & $29(15.9 \%)$ \\
\hline serum creatinine; mg/dl & $0.94 \pm 0.27$ \\
\hline elevated serum creatinine & $27(14.8 \%)$ \\
\hline CHADS 2 score: & \\
\hline CHADS2 $=0$ & $41(22.5 \%)$ \\
\hline CHADS2 $=1$ & $92(50.5 \%)$ \\
\hline CHADS2 $=2$ & $36(19.8 \%)$ \\
\hline CHADS2 $\geq 3$ & $13(7.1 \%)$ \\
\hline
\end{tabular}

Table 2 Clinical characteristics of patients with and without LA/LAA thrombus.

Tab. 2 Klinische Daten der Patienten mit sowie ohne Thrombus der LA-/LAA-Region.

\begin{tabular}{|c|c|c|c|}
\hline & $\begin{array}{l}\text { No LA/LAA } \\
\text { thrombus } \\
\mathrm{N}=177(97.3 \%)\end{array}$ & $\begin{array}{l}\text { LA/LAA } \\
\text { thrombus } \\
\mathrm{N}=5(2.7 \%)\end{array}$ & p-value \\
\hline male & $110(62.1 \%)$ & $4(80 \%)$ & n.s. \\
\hline female & $67(37.9 \%)$ & $1(20 \%)$ & n.s. \\
\hline age, mean & $64.03 \pm 8.88$ & $68.8 \pm 12.89$ & n.s. \\
\hline mean ejection fraction & $54.32 \pm 5.98$ & $48.60 \pm 7.77$ & n.s. \\
\hline paroxysmal atrial fibrillation & $116(65.5 \%)$ & $3(60 \%)$ & n.s. \\
\hline persistent atrial fibrillation & $61(34.5 \%)$ & $2(40 \%)$ & n.s. \\
\hline la size, $\mathrm{mm}$ & $45.26 \pm 6.86$ & $50.20 \pm 8.29$ & n.s. \\
\hline cardiomyopathy & $9(5.1 \%)$ & $0(0 \%)$ & n. s. \\
\hline mitral/aortic valve disease & $27(15.3 \%)$ & $2(40 \%)$ & n.s. \\
\hline serum creatinine; mg/dl & $0.93 \pm 0.27$ & $1.12 \pm 0.20$ & n. s. \\
\hline elevated serum creatinine & $25(14.1 \%)$ & $2(40 \%)$ & n.s. \\
\hline \multicolumn{4}{|l|}{ CHADS 2} \\
\hline congestive heart failure & $33(18.6 \%)$ & $1(20 \%)$ & n.s. \\
\hline hypertension & $111(62.7 \%)$ & $4(80 \%)$ & n.s. \\
\hline diabetes mellitus & $30(16.9 \%)$ & $4(80 \%)$ & 0.0004 \\
\hline prior stroke or TIA & $7(4.0 \%)$ & $0(0 \%)$ & n.s. \\
\hline age $\geq 75$ years & $12(6.8 \%)$ & $3(60 \%)$ & $<0.0001$ \\
\hline CHADS2 $=0$ & $41(23.2 \%)$ & $0(0 \%)$ & n.s. \\
\hline CHADS2 = 1 & $92(52.0 \%)$ & $0(0 \%)$ & 0.009 \\
\hline CHADS2 $=2$ & $33(18.6 \%)$ & $3(60 \%)$ & 0.02 \\
\hline CHADS $2 \geq 3$ & $11(6.2 \%)$ & $2(40 \%)$ & 0.004 \\
\hline
\end{tabular}

and LA assessment was feasible in all cases. The mean age was $64.1 \pm 10.2$ years with a male predominance (62.6\%). Paroxysmal AF was present in $65.4 \%$ of patients whereas $34.6 \%$ showed persistent AF. $78 \%$ of patients were treated with phenprocumon at the time of MDCT and TEE exam, and 17\% used aspirin only for anticoagulation. No adverse events were reported during TTE/ TEE and MDCT examination. Examinations were performed within 3 days ( 2 days \pm 1 ). MDCT identified 14 of 182 patients with filling defects or thrombus formation in LA or LAA (๑ Fig. 2). In 5 cases definitive thrombus formation was detected in LAA and confirmed by TEE; in 9 patients slow flow filling de-
Table 3 Filling defects in MDCT and suspicious findings detected by TEE.

Tab. 3 Füllungsdefekte im MDCT und suspekte Befunde detektiert mittels TEE.

\begin{tabular}{|lllcr}
\hline \multirow{2}{*}{ MDCT } & \multicolumn{2}{c}{ TEE } & & \\
\cline { 2 - 4 } & & thrombus or SEC & no thrombus or SEC & total \\
& $\begin{array}{l}\text { thrombus or } \\
\text { filling defects }\end{array}$ & 14 & 0 & 14 \\
& $\begin{array}{l}\text { no thrombus or } \\
\text { filling defects }\end{array}$ & 2 & 166 & 168 \\
\hline Total & 16 & 166 & 182
\end{tabular}

Sensitivity $87.5 \%$, specificity $100 \%$, NPV $98.8 \%$, PPV $100 \%$

Sensitivität 87,5\%, Spezifität 100\%, NPW 98,8\%, PPW $100 \%$

Table 4 Definite thrombus formation using LAA/AA ratio as a cutoff tool in MDCT, confirmed by TEE.

Tab. 4 Thrombusdetektion im MDCT unter Verwendung des LAA-/AA-Quotienten und bestätigt durch die TEE.

\begin{tabular}{|c|c|c|c|c|}
\hline & & TEE & & \\
\hline \multirow[t]{3}{*}{ MDCT } & & thrombus & no thrombus & total \\
\hline & thrombus & 5 & 0 & 5 \\
\hline & no thrombus & 0 & 177 & 177 \\
\hline Total & & 5 & 177 & 182 \\
\hline
\end{tabular}

Sensitivity $100 \%$, specificity $100 \%$, NPV $100 \%$, PPV $100 \%$ Sensitivität $100 \%$, Spezifität 100\%, NPW $100 \%$, PPW $100 \%$

fects were identified and judged as thrombotic precursors in the state of circulatory stasis. TEE identified 16 of 182 patients with spontaneous echo contrast (SEC) in the LA or LAA. In the same 5 patients as identified in cardiac MDCT, TEE detected definitive thrombus formation in the LAA ( $\bullet$ Table 2 ). Of the remaining 11 patients with evidence of SEC, 9 patients showed corresponding changes of circulatory stasis filling defects in MDCT (3 of them with paroxysmal AF). Two cases of SEC-equivalence in TEE were missed by cardiac MDCT. Neither echocardiography nor MDCT identified thrombus or thrombotic precursors in the LA body. All pathologic changes were seen in the LAA. Detailed results are listed in 0 Table 3, 4. Assuming TEE as the standard of reference for the detection of thrombus or slow-flow filling defects, MDCT resulted in a sensitivity of $87.5 \%$, specificity of $100 \%$, a negative predictive value (NPV) of $98.8 \%$ and a positive predictive value (PPV) of $100 \%$. There were no false-positive findings in MDCT in comparison to TEE. Quantitative analysis yielded a cut-off value for relative contrast enhancement of 0.5 (LA/LAA to AAo) for thrombus formation in LAA or LA: A LA/LAA to AAo relative contrast enhancement of $\leq 0.5$ as proposed by Hur et al. [17] correlated to all detected thrombi by TEE. In comparison to TEE, there was no detected thrombus in MDCT with an LA/LAA ratio $\geq 0.5$ ( $\bullet$ Fig. 1 ). Applying a value of $\leq 0.5$ relative contrast enhancement in MDCT as a threshold of thrombus formation, the overall sensitivity, specificity, NPV and PPV were $100 \%$. Patients with detected LA/LAA thrombus (5 of 182, 2.7\%) showed larger LA diameters ( $50 \pm 8 \mathrm{~mm}$ versus (vs.) $45 \pm 7 \mathrm{~mm}$ ), a lower mean ejection fraction ( $54 \pm 6 \%$ vs. $48 \pm 7 \%$ ), relatively more patients with mitral or aortic valve disease ( $40 \%$ vs. $15.3 \%$ ) and a higher serum creatinine $(\mathrm{mg} / \mathrm{dl})(0.93 \pm 0.27$ vs. $1.12 \pm 0.2)$. There was no detected LA/LAA thrombus in patients with a CHADS2 score $\leq 1$ and an age $\leq 50$ years. According to the CHADS2 score, diabetes mellitus ( $16.9 \%$ vs. $80 \%$, p-value 0.0004 ) and age $\geq 75$ 


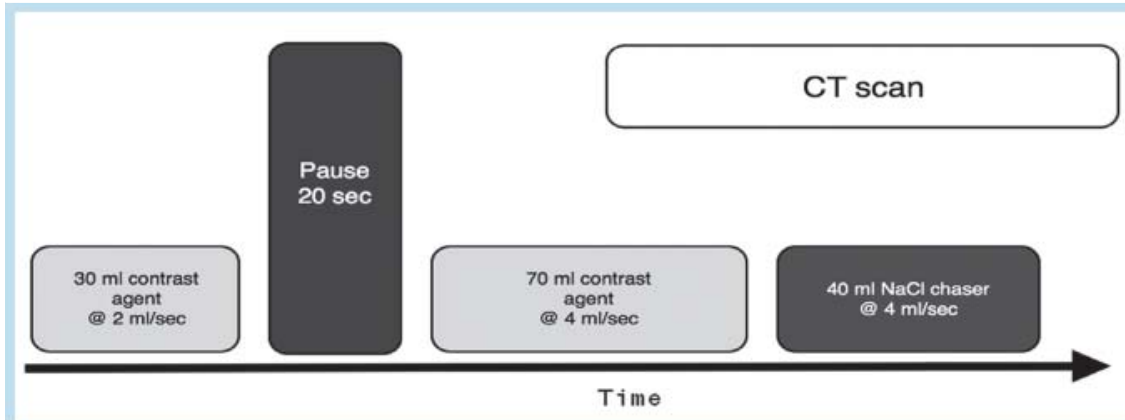

Fig. 2 Contrast injection protocol used in our study for pre-saturating the blood pool.

Abb. 2 Kontrast-Injektionsprotokoll dieser Studie verwendet für die Vorsättigung des Blut-Pooles.

(6.8\% vs. $60 \%$, p-value $<0.0001$ ) were significantly more prevalent in patients with LA/LAA thrombus. A subgroup analysis of patients with detected SEC on TEE revealed significantly higher CHADS2 scores than in patients without SEC $(p=0.02 ; r=0.69)$. Significantly higher CHADS2 scores were more prevalent in patients with thrombus (CHADS $2=2 ; 18.6 \%$ vs. $60 \%$, p-value 0.02 and CHADS $2 \geq 3 ; 6.2 \%$ vs. $40 \%$, p-value 0.004 ). There was good interobserver agreement for mean LAA/AA HU ratios for thrombus, filling defect, and normal groups $(r=0.984, r=0.948$ and $r=0.920$, respectively) ( Fig. $3-5$ ). The characteristics of the 5 patients (2.7\%) with LA/LAA thrombus are shown in $\bullet$ Table 2.

\section{Discussion \\ $\nabla$}

\section{Main finding}

This study aimed to prove the diagnostic accuracy of a split-contrast bolus in combination with single-phase cardiac MDCT in the clinical routine to rule out LA/LAA thrombi in patients with AF prior to PVI. The main finding of this study is that the presented contrast injection protocol combined with an LA/LAA to AAo HU ratio $\geq 0.5$ on MDCT and a pre-procedural CHADS2-score of $\leq 1$ were able to exclude thrombi with an NPV of $100 \%$.

\section{Detection of LA/LAA thrombus formation prior to PVI}

Prior to PVI it is mandatory to rule out LA/LAA thrombus formation to minimize the risk of periprocedural thromboembolic strokes during or after catheter ablation in the LA. In this context, TEE is known as an effective and reproducible method for ruling out intracavitary thrombi and it therefore currently remains the gold standard for assessing LA/LAA thrombus formation [2]. In many centers MDCT prior to PVI is usually performed to define the exact anatomy and dimensions of the LA and the insertions of the pulmonary veins. Within the same scan MDCT imaging is also used to rule out LA/LAA thrombus formation [17, 18]. Various study protocols for the detection of LA/LAA thrombus have been described and discussed in the past decade $[9,10,17,19-$ 26]. Usually nonionic iodinated contrast agent is used in a singlebolus injection with monophasic or biphasic CT protocols [9-12, 17, 27]. It still remains a major limitation of MDCT that incomplete contrast filling of the LAA is the most frequent cause of false-positive thrombus formation in the LAA, leading to a low specificity and a low PPV of about $30 \%[17,18,24]$.

\section{MDCT in pre-procedural management prior to $\mathrm{PVI}$}

When using MDCT for the detection of LA/LAA thrombus in patients with $A F$, it still remains very important to reliably discriminate between thrombus formation and non-thrombotic filling defects. Recently, Hur et al. introduced an LA/LAA-AAo ratio of
HU attenuation values [17] to evaluate thrombotic formations in the LA/LAA region. The mean HU values in the region of interest in the LA or LAA are divided by the mean attenuation value in the ascending aorta (AA). A cutoff value of $\leq 0.5$ was shown by Hur et al. $[17,27]$ to represent thrombus formation in the LA/LAA region. In concordance with these findings, in the recent study all 5 thrombi detected in TEE were correctly identified on MDCT with $100 \%$ diagnostic accuracy using LAA/AA ratio $\leq 0.5$ as a cutoff value. Comparable to our study, Hur et al. [27] recently introduced a double-injection contrast protocol to overcome incomplete contrast filling of the LA/LAA. Biphasic MDCT resulted in a high sensitivity and specificity for the detection of LA/LAA thrombus, but it is associated with a significant increase in radiation exposure compared to single-phase cardiac MDCT [8]. To avoid an increase in radiation exposure with comparable PPV and NPV as seen with the biphasic MDCT protocol, we also used a split-bolus injection protocol with a pre-saturation of the blood pool and a second contrast injection boost during single-phase MDCT ( $\bullet$ Fig. 2, - Table 3, 4).

\section{Role of spontaneous echo contrast}

Spontaneous echo contrast (SEC) in TEE is a common finding and can be found especially in patients with AF due to local circulatory stasis in the LA/LAA region $[21,22,26]$. It has to be considered that SEC is by definition not identical to thrombus formation in TEE and is therefore not a contraindication for the ablation procedure. Nevertheless, it has been described to be associated with a higher incidence of thrombus formation [23] in patients with AF and therefore SEC is an important finding in the pre-procedural management prior to an invasive ablation procedure in the LA [27]. Thus, Wazni et al. [23] reported no increase of peri-procedural stroke if SEC was identified in TEE and in addition even adequate anticoagulation did not have an influence on the degree or presence of SEC. Referring to this fact, in our study 11 patients showed SEC in TEE and 9 of 11 patients with SEC in TEE had nonthrombotic filling defects in MDCT defined as filling defects in the LAA with an LAA/AA ratio > 0.5. In two patients with detected SEC in TEE, no contrast abnormalities were detected in MDCT. The incidence of left atrial SEC rises with an increasing CHADS2 score which is in line with previous data from Scherr et al. [21]. The pre-saturation of the blood pool within the double-phase injection protocol consistently showed high $\mathrm{HU}$ attenuation values in the LAA region. It seems to reduce non-thrombotic filling defects by more complete contrast filling of the LAA and LA. The clinical interpretation of SEC (without thrombus) is still a clinical challenge. Probably, in the presence of structural changes, such as LA enlargement, a higher INR target should also be adopted in this specific setting. Further randomized studies are needed to confirm these results. 

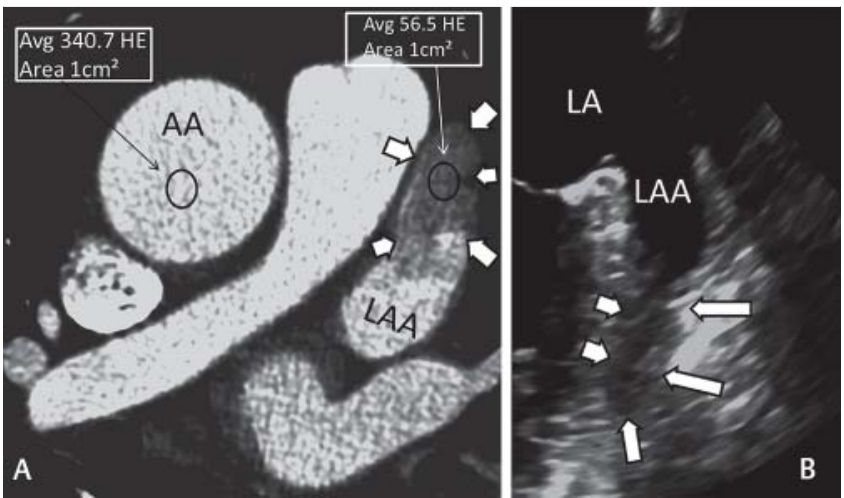

Fig. 3 Cardiac MDCT A and transesophageal echocardiography (TEE) B from a 51-year-old male patient with left atrial appendage thrombus prior to PVI. MDCT demonstrates a filling defect (arrows) of the LAA with LAA/ AA density ratio 0.17 and corresponding thrombus in TEE (arrows).

Abb. 3 Kardio-MDCT A und transösophageale Echokardiografie(TEE) B von einem 51-jährigen männlichen Patienten mit Thrombus des linken Herzohrs vor PVI. Kardio-MDCT zeigt einen Thrombus (Pfeile) des LAA mit LAA-|AA-Dichte-Verhältnis von 0,17 und entsprechendem Thrombus im TEE (Pfeile).
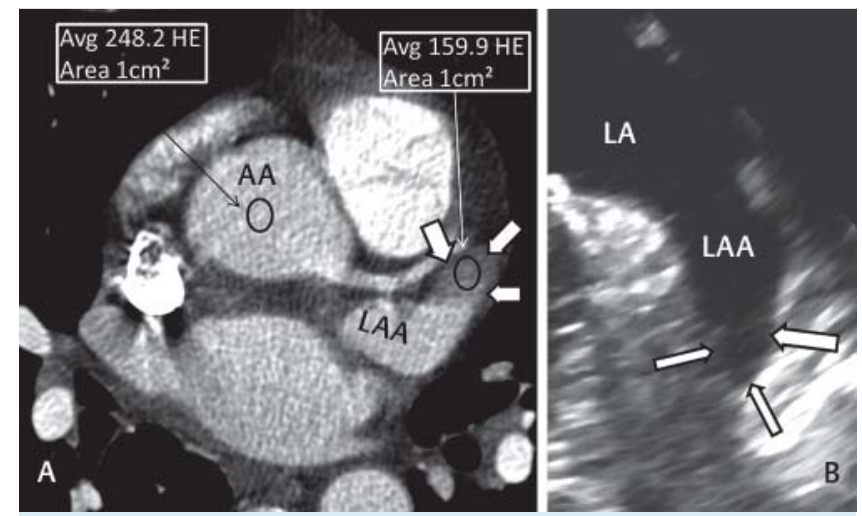

Fig. 4 Incomplete filling defect of LAA in cardiac MDCT A and transesophageal echocardiography $\mathbf{B}$ from a 63-year-old male patient prior to PVI. MDCT demonstrates a typical oval filling defect (arrows) with a LAA/AA density ratio of 0.65 . TEE depicts SEC (arrows) on the same day without thrombus, corresponding to the MDCT results.

Abb. 4 Unvollständiger Füllungsdefekt des LAA im Kardio-MDCT A und TEE B von einem 63 Jahre alten männlichen Patienten vor PVI. KardioMDCT zeigt einen typischen ovalen Füllungsdefekt (Pfeile) mit einem LAA-/AA-Dichte-Verhältnis von 0,65. Im TEE vom selben Tag zeigt sich ein Spontankontrast (Pfeile) jedoch kein Thrombus, entsprechend des MDCT Ergebnisses.

\section{Risk factors for LA/LAA thrombus formation}

Previous TEE studies in patients with AF undergoing PVI showed a wide range of LA/LAA thrombus prevalence ( $0.5 \%$ up to $13.8 \%$ ) $[19,20]$. Scherr et al. reported a $1.9 \%$ incidence of LA thrombus formation prior to PVI [21] in a cohort of 635 patients. This is in line with the findings of our study showing a prevalence of LA/ LAA thrombus formation of $2.7 \%$. It still remains questionable if there are certain risk factors that can reliably predict thrombus formation in patients with AF. As previously mentioned, it is common to use the CHADS2 score to validate for estimating the risk of cerebral thromboembolic stroke in patients with AF [5, 26]. An LA size of $45 \mathrm{~mm}$ evaluated at a $75 \%$ RR interval in
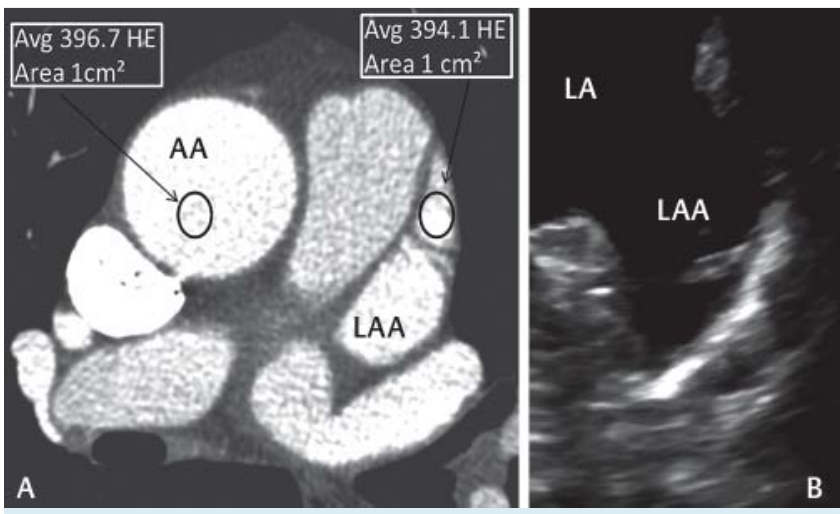

Fig. 5 Cardiac MDCT A and transesophageal echocardiography B from a 71-year-old female patient prior to PVI. CT demonstrates fully opacified LA/ $L A A$ region with trabeculated structure and no filling defect in the LAA. LAA/AA ratio was 0.99 . Corresponding TEE shows trabeculated structure in the LAA without SEC or thrombus.

Abb. 5 Kardio-MDCT A und TEE B von einer 71-jährige Patientin vor PVI. Im MDCT zeigt sich die LA-/LAA-Region mit Trabekularisierung und ohne Füllungsdefekt im Vorhofohr. Der LAA-/AA-Quotient betrug 0,99. Das korrespondierende TEE zeigt die Trabekularisation im Vorhofohr ohne Spontankontrast oder Thrombus.

MDCT and CHADS2 score $\geq 2$ were shown to be independent risk factors for LA/LAA thrombus in our study which is in concordance with the published literature $[17,18]$. Apart from LA size and CHADS2 score, Dorenkamp et al. identified the presence of diabetes mellitus as a single independent risk factor of LAA thrombus [18]. In this context, all 5 thrombi identified by MDCT in our study were found in patients with a CHADS2 score of $\geq 2$ in combination with diabetes mellitus. There was no thrombus detected in MDCT or TEE in patients with an age $\leq 50$ and a CHADS2 score $\leq 1$. Despite an effective anticoagulation - based on a CHADS2 $\geq 2-5$ of 182 patients with AF undergoing MDCT and TEE prior to PVI showed LA/LAA thrombus formation.

\section{Limitations}

MDCT supplies high-resolution volumetric data sets of the heart and its related anatomical structures that are used to guide PVI. For optimal visualization of cardiac anatomy beyond the LA, we used the cardiac phase of $75 \%$ RR-interval of the retrospectively gated cardiac MDCT datasets. TEE was considered the reference standard, and the presence or absence of left atrium thrombus was not confirmed by direct visual inspection of anatomic or surgical specimen. Further studies need to evaluate the accuracy of thrombus detection in the LA/LAA region with an increased scan delay approach and/or using dual bolus strategies with an additional saline chaser after the first contrast medium injection. Despite that, TTE and cardiac MDCT were not performed on the same day. However, initial experience with dual-source CT (DSCT) at our institution using the same contrast injection protocol and a prospective trigger approach looks promising in regard to PPV and NPV for thrombus formation in the LA or LAA while significantly reducing radiation exposure to about $<1-3 \mathrm{mSv}$.

\section{Conclusion}

\section{$\nabla$}

MDCT was $100 \%$ accurate for thrombus with strong but not perfect overall results for SEC-equivalence on MDCT. In the clinical 
routine, patients with no filling defect or thrombus in MDCT in the LA/LAA region are unlikely to have thrombus and may undergo PVI without TEE. This might redefine the role of an additional TEE in pre-procedural management prior to PVI in patients with AF.

\section{Clinical implication}

\section{$\nabla$}

In patients with an LAA/AA ratio $\geq 0.5$ on MDCT and a CHADS2 score $\leq 1$, TEE may be safely avoided.

\section{References}

1 Calkins H, Brugada J, Packer DL et al. HRS/EHRA/ECAS expert consensus statement on catheter and surgical ablation of atrial fibrillation: recommendations for personnel, policy, procedures and follow-up. A report of the Heart Rhythm Society (HRS) Task Force on catheter and surgical ablation of atrial fibrillation. HeartRhythm 2007; 4: 816-861

2 Atrial Fibrillation Investigators. Risk factors for stroke and efficacy of antithrombotic therapy in atrial fibrillation: Analysis of pooled data from five randomized controlled trials. Arch Intern Med 1994; 154: $1449-1457$

3 Dong J, Dickfeld T, Dalal D et al. Initial experience in the use of integrated electroanatomic mapping with three-dimensional MR/CT images to guide catheter ablation of atrial fibrillation. J Cardiovasc Electrophysiol 2006; 17: 459-466

4 Fuster V, Ryden LE, Cannom DS et al. ACC/AHA/ESC 2006 Guidelines for the Managementof Patients with Atrial Fibrillation: a report of the American College of Cardiology/American Heart Association Task Force on Practice Guidelines and the European Society of Cardiology Committee for Practice Guidelines (Writing Committee to Revise the 2001 Guidelines for the Management of Patients With Atrial Fibrillation): developed in collaboration with the European Heart Rhythm Association and the Heart Rhythm Society. Circulation 2006; 114: $257-354$

5 Gage $B F$, van Walraven $C$, Pearce $L$ et al. Selecting patients with atrial fibrillationfor anticoagulation: stroke risk stratification in patients taking aspirin. Circulation 2004; 110: 2287-2292

6 Carerj S, Trifiro MP, Granata A et al. Comparison between transeophageal echocardiography and transthoracic echocardiography with harmonic tissue imaging for left atrial appendage assessment. Clin Cardiol 2002; 25: 268-270

7 Jaber WA, White RD, Kuzmiak SA et al. Comparison of ability to identify left atrial thrombus by three-dimensional tomography versus transesophageal echocardiography in patients with atrial fibrillation. Am J Cardiol 2004; 93: 486-489

$8 \mathrm{Kim}$ YY, Klein AL, Halliburton SS et al. Left atrial appendage filling defects identified by multidetector computed tomography in patients undergoing radiofrequency pulmonary vein antral isolation: a comparison with transesophageal echocardiography. Am Heart J 2007; 154: $1199-1205$

9 Patel A, Au E, Donegan $K$ et al. Multidetector row computed tomography for identification of left atrial appendage filling defects in patients undergoing pulmonary vein isolation for treatment of atrial fibrillation: comparison with transesophageal echocardiography. Heart Rhythm 2008; 5: 253-260

10 Gottlieb I, Pinheiro A, Brinker JA et al. Diagnostic accuracy of arterial phase 64slice multidetector CT angiography for left atrial appendage thrombus in patients undergoing atrial fibrillation ablation. J Cardiovasc Electrophysiol 2008; 19: 247-251

11 Tang RB, Dong JZ, Zhang ZQ et al. Comparison of contrast enhanced 64slice computed tomography and transesophageal echocardiography in detection of left atrial thrombus in patients with atrial fibrillation. J Interv Card Electrophysiol 2008; 22: 199-203

12 Martinez M, Kirsch J, Williamson EE et al. Utility of nongated multidetector computed tomography for detection of left atrial thrombus in patients undergoing catheter ablation of atrial fibrillation. J Am Coll Cardiol Img 2009; 2: 69-76

13 Lang RM, Bierig M, Devereux RB et al. Recommendations for chamber quantification: a report from the American Society of Echocardiography's Guidelines and Standards Committee and the Chamber Quantification Writing Group, developed in conjunction with the European Association of Echocardiography, a branch of the European Society of Cardiology. J Am Soc Echocardiogr 2005; 18: 1440-1463

14 Go AS, Fang MC, Udaltsova N et al. Impact of proteinuria and glomerular filtration rate on risk of thromboembolism in atrial fibrillation: the Anticoagulation and Risk Factors in Atrial Fibrillation (ATRIA) Study. Circulation 2009; 119: $1363-1369$

15 Fatkin D, Kelly RP, Feneley MP. Relations between left atrial appendage blood flow velocitiy, spontaneous echocardiographic contrast and thromboembolic risk in vivo. J Am Coll Cardiol 1994; 23: 961 -969

16 Choi SI, George RT, Schuleri KH et al. Recent developments in wide - detector cardiac computed tomography. Int J Cardiovasc Imaging 2009; 25: $23-29$

17 Hur J, Kim YJ, Lee HJ et al. Left atrial appendage thrombi in stroke patients: detection with two-phase cardiac CT angiography versus transesophageal echocardiography. Radiology 2009; 251: 683-690

18 Dorenkamp M, Sohns C, Vollmann D et al. Detection of left atrial thrombus during routine diagnostic work-up prior to pulmonary vein isolation for atrial fibrillation: Role of transesophageal echocardiography and multidetector computed tomography. Int J Cardiol 2011; 11: $681-684$

19 Khan MN, Usmani A, Noor S et al. Low incidence of left atrial or left atrial appendage thrombus in patients with paroxysmal atrial fibrillation and normal $\mathrm{EF}$ who present for pulmonary vein antrum isolation procedure. J Cardiovasc Electrophysiol 2008; 19: 356- 358

20 Thambidorai SK, Murray RD, Parakh K et al. Utility of transesophageal echocardiography in identification of thrombogenic milieu in patients with atrial fibrillation (an ACUTE ancillary study). Am J Cardiol 2005; 96: 935-941

21 Scherr D, Dalal D, Chilukuri K et al. Incidence and predictors of left atrial thrombus prior to catheter ablation of atrial fibrillation. J Cardiovasc Electrophysiol 2009; 20: 379-384

22 Sawit ST, Garcia-Alvarez A, Suri B et al. Usefulness of Cardiac Computed Tomographic Delayed Contrast Enhancement of the Left Atrial Appendage Before Pulmonary Vein Ablation. Am J Cardiol 2012; 109: 677-684

23 Wazni OM, Beheiry S, Fahmy T et al. Atrial fibrillation in patients with therapeutic international normalized ratio: Comparison of strategies of anticoagulation management in the periprocedural period. Circulation 2007; 116: $2531-2534$

24 Tsai LM, Chen JH, Lin LJ et al. Natural history of left atrial spontaneous echo contrast in nonrheumatic atrial fibrillation. Am J Cardiol 1997; 80: $897-900$

25 Bischoff B, Hein F, Meyer T et al. Comparison of sequential and helical scanning for radiation dose and image quality: results of the Prospective Multicenter Study on Radiation Dose Estimates of Cardiac CT Angiography (PROTECTION) I study. Am J Roentgenol 2010; 194: $1495-1499$

26 Floria M, De Roy L, Xhaet $O$ et al. Predictive Value of Thromboembolic Risk Scores Before an Atrial Fibrillation Ablation Procedure. J Cardiovasc Electrophysiol 2013; 24: 139-145

27 Rubin DN, Katz SE, Riley MF et al. Evaluation of left atrial appendage anatomy and function in recent-onset atrial fibrillation by transesophageal echocardiography. Am J Cardiol 1996; 78: 774-778

28 Hur J, Pak HN, Kim YJ et al. Dual-enhancement cardiac computed tomography for assessing left atrial thrombus and pulmonary veins before radiofrequency catheter ablation for atrial fibrillation. Am J Cardiol 2013; 112: 238-244 